This item was submitted to Loughborough's Research Repository by the author.

Items in Figshare are protected by copyright, with all rights reserved, unless otherwise indicated.

\title{
Mathematical modeling, design, and optimization of a multisegment multiaddition plug-flow crystallizer for antisolvent crystallizations
}

\section{PLEASE CITE THE PUBLISHED VERSION}

http://dx.doi.org/10.1021/acs.oprd.5b00110

\section{PUBLISHER}

(c) American Chemical Society

\section{VERSION}

AM (Accepted Manuscript)

\section{PUBLISHER STATEMENT}

This work is made available according to the conditions of the Creative Commons Attribution-NonCommercialNoDerivatives 4.0 International (CC BY-NC-ND 4.0) licence. Full details of this licence are available at: https://creativecommons.org/licenses/by-nc-nd/4.0/

\section{LICENCE}

CC BY-NC-ND 4.0

\section{REPOSITORY RECORD}

Su, Qinglin, Brahim Benyahia, Zoltan K. Nagy, and Chris D. Rielly. 2016. "Mathematical Modeling, Design, and Optimization of a Multisegment Multiaddition Plug-flow Crystallizer for Antisolvent Crystallizations". figshare. https://hdl.handle.net/2134/20216. 


\section{Organic Process \\ Research \& Development}

Subscriber access provided by LOUGHBOROUGH | UNIVERSITY LIBRARY

\section{Full Paper}

\section{Mathematical modeling, design, and optimization of a multi-segment multi-addition plug-flow crystallizer for anti-solvent crystallizations QINGLIN SU, Brahim Benyahia, Zoltan K. Nagy, and Chris D. Rielly}

Org. Process Res. Dev., Just Accepted Manuscript • DOI: 10.1021/acs.oprd.5b00110 • Publication Date (Web): 11 Sep 2015 Downloaded from http://pubs.acs.org on September 14, 2015

\section{Just Accepted}

"Just Accepted" manuscripts have been peer-reviewed and accepted for publication. They are posted online prior to technical editing, formatting for publication and author proofing. The American Chemical Society provides "Just Accepted" as a free service to the research community to expedite the dissemination of scientific material as soon as possible after acceptance. "Just Accepted" manuscripts appear in full in PDF format accompanied by an HTML abstract. "Just Accepted" manuscripts have been fully peer reviewed, but should not be considered the official version of record. They are accessible to all readers and citable by the Digital Object Identifier (DOI®). "Just Accepted" is an optional service offered to authors. Therefore, the "Just Accepted" Web site may not include all articles that will be published in the journal. After a manuscript is technically edited and formatted, it will be removed from the "Just Accepted" Web site and published as an ASAP article. Note that technical editing may introduce minor changes to the manuscript text and/or graphics which could affect content, and all legal disclaimers and ethical guidelines that apply to the journal pertain. ACS cannot be held responsible for errors or consequences arising from the use of information contained in these "Just Accepted" manuscripts. 


\title{
Mathematical modeling, design, and optimization of a multi-segment multi-addition plug-flow
}

\section{crystallizer for anti-solvent crystallizations}

\author{
Qinglin Su ${ }^{1, *}$, Brahim Benyahia ${ }^{1}$, Zoltan K. Nagy ${ }^{1,2}$, Chris D. Rielly ${ }^{1, *}$ \\ ${ }^{1}$ Department of Chemical Engineering, Loughborough University, Loughborough, LE11 3TU, \\ UK. \\ ${ }^{2}$ School of Chemical Engineering, Purdue University, West Lafayette, IN 47907-2100, USA.
}

\section{Corresponding Author}

* To whom correspondence should be addressed: E-mail: Q.Su@lboro.ac.uk or C.D.Rielly@lboro.ac.uk; Tel: +44 (0) 1509222504 


\section{TABLE OF CONTENTS GRAPHIC}

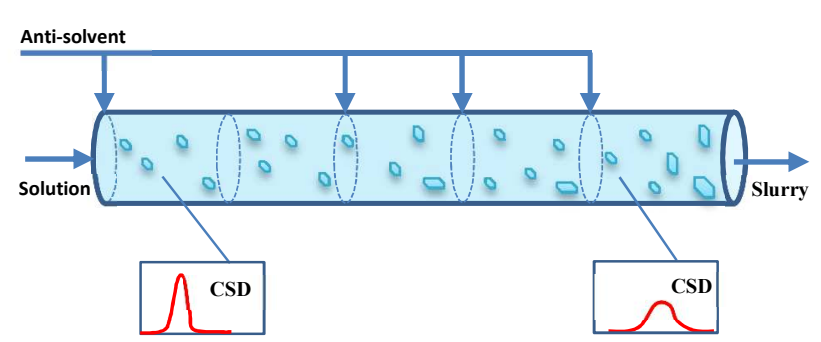

CSD: Crystal size distribution 
ABSTRACT: In the pharmaceutical industries, the requirements of rapid process development and scalable design have made the tubular crystallizer a promising platform for continuous manufacturing and crystallization processes, capable of replacing conventional capital- and labor-intensive batch operations. This paper takes a process systems engineering (PSE) approach to the optimal design of a continuous anti-solvent addition crystallizer to deliver the most promising product qualities, such as the crystal size distribution. A multi-segment multi-addition plug-flow crystallizer (MSMA-PFC) is considered as an example of a continuous anti-solvent crystallization processes, in which the total number, location, and distribution of anti-solvent additions are to be optimized. First principles dynamic and steady-state mathematical models for the MSMA-PFC are presented, based on example kinetic models for nucleation and growth of paracetamol crystallizing in acetone, with water as the anti-solvent. The performances of different crystallizer configurations operated under optimal design conditions are then compared. The configuration in which anti-solvent could be added at a variety of different locations along the tube length and at optimal flow rates was able to outperform previous designs in the literature which considered equally-spaced anti-solvent additions. The use of dynamic models to detect problems during startup of an MSMA-PFC was also highlighted.

KEYWORDS: Tubular crystallizer; mathematical modelling; crystallizer design; optimization; anti-solvent. 


\section{INTRODUCTION}

Crystallization is a common unit operation for separation and purification and is used for approximately $90 \%$ of organic molecules in the pharmaceutical and fine chemical sectors ${ }^{1-3}$. Traditionally, batch operations have been used for the crystallization stage and for downstream secondary manufacturing processes, as they provide a flexible way to meet the stringent regulations for product quality and the variable demands of the market. However, rising market competition and the need to reduce manufacturing costs are driving the future of pharmaceutical and fine chemical industries towards continuous processes, which have potential for improvements in product quality, through on-line process monitoring and control, and reduced equipment footprint, energy and labor $\operatorname{costs}^{4-7}$.

Over the last decade, the development of continuous manufacturing and purification processes, particularly crystallization, has mainly focused on the modification of existing batch units $^{8-10}$, in addition to studying innovative equipment design. Batch crystallizers are often based around stirred-tank technologies, which can be converted to continuous mode as multi-stage mixed-suspension and mixed product removal (MSMPR) operations ${ }^{11-16}$, but they suffer from broad residence time distributions, leading to broad crystal size distributions and problems in downstream processes, such as filtration, isolation, drying and solids mixing. Consequently, interest in tubular designs of continuous crystallizer has increased in recent years, because of the potential benefits of a much narrower residence time distribution, enhanced control of the supersupersaturation and the ease of scaling-up from pilot to full-scale operation.

Recent research efforts have been devoted to the experimental investigation of tubular crystallizers. For example, Lawton et al. ${ }^{17}$ reported the application of a continuous oscillatory 
baffled crystallizer (COBC) for a cooling crystallization which offered significant advantages in operating cost and processing time. $\operatorname{Eder}^{18-19}$ and his colleagues investigated the impacts of flow rate and seed loading in continuously-seeded tubular cooling crystallizers for the production of active pharmaceutical ingredients (APIs). Ferguson et al. ${ }^{20}$ reported the employment of a variety of process analytical technology (PAT) tools for particle size and solute concentration measurement in a plug flow crystallizer. Such PAT tools provide time-varying measurements at a single spatial location, but do not reveal the evolution of the CSD or solute concentration profile with increasing residence time in the flow device. These experimental studies provide valuable insight into the performance of tubular crystallizers, but with limited information about spatial evolution; moreover they show that there is a complex interaction of effects involving the flow configuration, the use of seeding, the supersaturation profile and the nucleation and growth kinetics on the final product qualities, such as the crystal size distribution. Without a process systems model, they could only provide qualitative indications of how to optimize the crystallizer design to produce crystals with a target size distribution, or of particular shape or polymorph type. Thus the design of such continuous processes is complicated by the interaction of numerous operating variables, which affect the supersaturation profile and the product quality, in terms of its CSD. A purely experimental investigation of the crystallizer operating space would be time-consuming and difficult to interpret; hence the operation would be almost impossible to design and optimize without a model framework.

Other studies make use of first-principles models, alongside experimental studies, to deduce the optimal operating conditions to produce crystals of a specified size. For example, Alvarez and Myerson ${ }^{1}$ modelled and conducted experiments on a multi-segment, multi-addition plugflow crystallizer (MSMA-PFC) with anti-solvent addition empirically distributed along the tube 
and showed how the device could be operated to produce crystals of a small mean size and narrow CSD. Zhou et al. ${ }^{21}$, studied experimentally a novel concentric annulus to achieve layer crystallization, and formulated a model which predicted the profile of the temperature, concentration and crystal thickness along the pipe length; their model was used to optimize the crystal yield and the layer thickness.

Process systems engineering (PSE) approaches using mathematical modeling, intensification, and optimization are now being applied to the design of tubular crystallizers, e.g., by Lakerveld et al. ${ }^{22}$. Majumder and $\mathrm{Nagy}^{3}$ optimized the temperature profile along a multi-segment PFC, which included cooling and heating segments, with the objective of removing crystal fines by controlled dissolution. Vetter et al. ${ }^{23}$ recently investigated the attainable regions of particle sizes for a single-stage ideal plug-flow crystallizer, which assumed continuous addition of anti-solvent along the tube; they compared the achievable product qualities to those manufactured in MSMPR and batch crystallizers. Ridder et al. ${ }^{24}$ proposed a simultaneous design and control (SDC) approach to optimize the number of segments and anti-solvent distributions along a MSMA-PFC for an anti-solvent crystallization processes. More specifically, recent studies by Kwon et al. ${ }^{25}$ also focused on the multi-segment plug-flow crystallizer to control the crystal shape and size distribution by optimizing jacket temperature for each segment. These simulations are based on first-principles process systems models using spatially-distributed mass, heat and population balances and include the various complexities in crystallization, such as the effect of anti-solvent addition, which may increase or decrease the supersaturation depending on the slope of the solubility curve. Moreover, these flow sheet simulations of continuous crystallizers are often based on bespoke code, since plug flow modules are not yet available in commercial 
software packages, such as the gCRYSTAL 4.0 software offered by Process System Enterprises Ltd.

The study reported here is part of a larger project to build dynamic simulations of continuous crystallization and downstream secondary manufacturing operations, to optimize performance and test out control strategies for an integrated pharmaceutical production plant flow sheet. This paper presents an example of the first stage, which considers the mathematical modeling, design, and optimization of tubular crystallizers for anti-solvent crystallization, to provide a better understanding of flexible design, and to improve the process performance accordingly. Dynamic models are used to examine the non-linear system response to external manipulations or disturbances for process control purpose and can be applied to design start-up and shut-down procedures, where changes of operating states are required with minimal production of waste or off-specification product. The optimal design of such transient operations is critical for a costeffective continuous process, particularly when the production capacity is scaled up and/or the manufacturing time is short ${ }^{26}$. In contrast, a steady-state model is computationally more efficient when dealing with process design and optimization. However, dynamic models are still required to confirm that the optimal operating conditions from a steady-state model are obtained reliably and lead to stable operation.

The multi-segment multi-addition design of a plug-flow crystallizer is a generalized type of anti-solvent crystallization which aims to provide accurate control of supersaturation and antisolvent mass fraction profiles along the length of the tube, as shown in Figure 1. The modular design of the PFC segments ${ }^{1}$, where flexibility is a key aspect, is intended for campaign production of different active pharmaceutical ingredients using the same processing line. This is an important consideration for the design of a continuous manufacturing process ${ }^{26}$. For example, 
varying lengths of tube and longer mean residence times can be obtained by assembling a greater number of PFC segments and the distribution of anti-solvent additions along the segments can be optimized to create different supersaturation profiles along the tube ${ }^{24}$, as indicated schematically in Figure 1.

This paper is organized as follows. Dynamic and steady-state mathematical models of a general plug-flow crystallizer are presented, followed by their extensions to a multi-segment multi-addition design for anti-solvent crystallization. Unlike the equally-spaced anti-solvent addition proposed by Ridder et al. ${ }^{24}$, the configuration studied here allows for optimization of both the locations and distributions of anti-solvent additions along the tubular crystallizer; a mixed integer non-linear programming (MINLP) optimization is used for this purpose. The results and discussion section considers the application of the proposed design and optimization framework to an anti-solvent crystallization of paracetamol in acetone with water as the antisolvent and compares its performance to other configurations reported in the literature. Finally, concluding remarks are made. 


\section{MATHEMATICAL MODELLING OF PLUG-FLOW CRYSTALLIZER}

In the pharmaceutical industries, a typical bulk API is usually produced at a rate of $>1$ tons per day $^{27}$ and thus the diameter of a tubular crystallizer could be of the order of a few centimeters, which is small when compared to the typical tube length (tens of meters). As a result, there is often near perfect mixing in the radial direction and limited dispersion in the axial direction, which means that the assumptions of a plug flow device are likely to apply. A relatively high slurry mean velocity along the tube is required to avoid the sedimentation of crystals (or, in the case of an oscillatory baffled crystallizer ${ }^{17}$, high-frequency oscillations are introduced to suspend the crystals and produce a narrow residence time distribution, but not perfect plug flow, as is discussed at the end of this section). Often it is reasonable to assume that the tubular crystallizer is a plug-flow crystallizer and therefore requires only one spatial dimension, i.e., the tube axial length, in a mathematical model.

The governing equations for a general segment of a plug-flow crystallizer are based on a population balance equation for the crystal size distribution and a mass balance equation for solute concentrations, as shown below:

$$
\begin{gathered}
\frac{\partial n}{\partial t}+\frac{\partial\left(v_{z} n\right)}{\partial z}+\frac{\partial(G n)}{\partial L}=S(n, L, z, t) \\
\frac{\partial \mathbf{C}}{\partial t}+\frac{\partial\left(v_{z} \mathbf{C}\right)}{\partial z}+\frac{3 \boldsymbol{\varphi} \rho_{s} K_{v}}{M_{w}} \int G L^{2} n d L=0
\end{gathered}
$$

In eqs.(1) and (2), $n$ is the number probability density function of crystals in the slurry, $\# / \mathrm{m}^{3} / \mathrm{m} ; t$ is the time, $\mathrm{s} ; v_{z}$ is the slurry superficial velocity along the tube axial, $\mathrm{m} / \mathrm{s} ; z$ is the tube axial coordinate, $\mathrm{m} ; G$ is the crystal growth rate, $\mathrm{m} / \mathrm{s} ; L$ is the characteristic length of crystal, m; $S$ 
represents the source and sink terms accounting for crystal breakage and agglomeration, $\# / \mathrm{m}^{3} / \mathrm{s}$; $\mathbf{C}$ is a vector representing molar concentrations of the various chemical species (including the solute, the anti-solvent and impurities if any, etc.), $\mathrm{kmol} / \mathrm{m}^{3} ; \boldsymbol{\varphi}$ is the chemometrics vector for the chemical species mole fractions in the crystal phase; $\rho_{s}$ is the crystal density, $\mathrm{kg} / \mathrm{m}^{3} ; K_{v}$ is the volumetric shape factor of crystal; $M_{w}$ is the mean molecular weight of the crystal, $\mathrm{kg} / \mathrm{kmol}$. In this study, a single crystal phase is considered, but extension of the balance equations to multiple crystal phases or to multiple polymorphs is straightforward.

The plug flow crystallizer is an unsteady and spatially-distributed system and hence the number density $n$ and solute concentrations $\mathbf{C}$ are both functions of position along the tube $z$ and time $t$; their boundary and initial conditions are listed below.

Boundary conditions for $n(L, z, t)$ and $\mathbf{C}(z, t)$ at $L=L_{0}$ or $z=0$ :

$$
\begin{gathered}
n\left(L_{0}, z, t\right)=\frac{B}{G} \\
n(L, 0, t)=n_{\text {feed }}(L, t) \\
\mathbf{C}(0, t)=\mathbf{C}_{\text {feed }}
\end{gathered}
$$

where $B$ is the nucleation rate, $\# / \mathrm{m}^{3} / \mathrm{s} ; L_{0}$ is the nuclei size, $\mathrm{m} ; n_{\text {feed }}$ is the number probability density function of the feed CSD at the crystallizer inlet, $\# / \mathrm{m}^{3} / \mathrm{m}$, which for example, is required for a seeded crystallization, or where a feed slurry is supplied from an upstream unit; $\mathbf{C}_{\text {feed }}$ represents the feed species concentrations at the crystallizer inlet, $\mathrm{kmol} / \mathrm{m}^{3}$.

The initial conditions for $n(L, z, t)$ and $\mathbf{C}(z, t)$ at $t=0$ :

$$
n(L, z, 0)=n_{0}(L, z)
$$




$$
\mathbf{C}(z, 0)=\mathbf{C}_{0}(z)
$$

where $n_{0}\left(\# / \mathrm{m}^{3} / \mathrm{m}\right)$ and $\mathbf{C}_{0}(\mathrm{kmol} / \mathrm{m} 3)$ are the initial number probability density function for the CSD and species concentrations, respectively, inside the crystallizer.

A steady-state model of a plug-flow crystallizer can be obtained straightforwardly by removing the time derivative terms of the crystal number density $n$ and solute concentrations $\mathbf{C}$ from the dynamic eqs.(1) and (2) and retaining the boundary conditions of eqs.(3) to (5) only. The slurry superficial velocity $v_{z}$ along the crystallizer is not necessarily constant, e.g., if the volume changes due to crystallization (formation of solids) along the crystallizer cannot be neglected $^{16}$, and hence $v_{z}$ will depend on the yield of crystals at each point along the crystallizer and should be rigorously calculated. For simplicity, we assume a constant slurry mean velocity $\bar{v}_{z}$ along the tube ${ }^{1}$ and there is no breakage or agglomeration in the tube. Hence the steady-state model can be simplified as follows.

$$
\begin{gathered}
\frac{\partial n}{\partial z}+\frac{1}{\bar{v}_{z}} \frac{\partial(G n)}{\partial L}=0 \\
\frac{d \mathbf{C}}{d z}+\frac{3 \boldsymbol{\varphi} \rho_{s} K_{v}}{\bar{v}_{z} M_{w}} \int G L^{2} n d L=0
\end{gathered}
$$

The above partial differential equations (PDEs) (1) and (2) for the dynamic model can be solved in MATLAB with a high-resolution finite-volume method (FVM) ${ }^{28}$ by discretizing both the tube axial length $z$ and the crystal characteristic length $L$ and then integrating the resulting set of ordinary differential equations (ODEs), together with eq.(2), with respect to the system time $t$ (i.e. using the method of lines). The FVM scheme is of second-order accuracy, combining a robust upwind discretization method with the novel $k=1 / 3$ flux limiter, capturing the sharp 
front of the nucleation boundary in eq.(3) without numerical oscillations, and providing a smooth solution. In terms of steady-state modelling of the population balance eq.(8), only discretization in crystal length $L$ and integration, together with the mass balance of eq.(9) for solute concentrations, along the tube length $z$ are necessary. All the integrations of ODEs were executed with the built-in "ode45" or "ode23" function for non-stiff problems in MATLAB.

Depending on the fineness of discretization in the FVM, the PDEs often result in tens or hundreds of ODEs which can be computationally expensive to solve. Alternatively, when the crystal growth rate $G$ is size independent, the classical method of moments (MOM) can also be applied to integrate the PDE (8) along the crystal length $L$ by conversion into a set of moment ODEs, which further reduces the computational burden for steady-state modeling. This is critically important when a large optimization problem is considered. In the MOM, the integration and moment transformation of the PDE into the first six moments are given below.

$$
\begin{gathered}
\mu_{k}=\int_{0}^{\infty} L^{k} n(L, z) d L, \quad k=0 \cdots 5 \\
\frac{d \mu_{0}}{d z}=\frac{B}{\bar{v}_{z}} \\
\frac{d \mu_{k}}{d z}=k\left(\frac{G}{\bar{v}_{z}}\right) \mu_{k-1}+\left(\frac{B}{\bar{v}_{z}}\right) L_{0}^{k}
\end{gathered}
$$

where $\mu_{k}$ is the $k^{\text {th }}$ moment of the number CSD probability density function $n, \mathrm{~m}^{k} / \mathrm{m}^{3}$. Although the full CSD development along the tube $z$ is lost by the integration of eq.(10), the physical meanings of the first few moments provide useful information: e.g., $\mu_{0}$ is the total particle number per volume of the slurry; $\mu_{3}$ is related to the total volume of crystals per volume of the slurry. Therefore, the volume-based mean crystal size $\left(L_{43}\right)$ and the coefficient of variation $(\mathrm{CV})$ 
of the full CSD still can be captured by the MOM, as shown in eqs. (13) and (14). Furthermore, after the optimization problem is solved based on the MOM model, the full CSD can be recovered by solving the full model of eqs. (8) and (9). In such a way, less-expensive function evaluations are possible for the optimization algorithms ${ }^{24}$. Identical results were obtained with MOM and FVM when a suitably fine level of discretization was employed ${ }^{29,} 30$.

$$
\begin{gathered}
L_{43}=\frac{\mu_{4}}{\mu_{3}} \\
C V=\sqrt{\frac{\mu_{5} \mu_{3}}{\mu_{4}^{2}}-1}
\end{gathered}
$$

The mathematical model could easily be extended to a $\mathrm{COBC}$, which is not a perfect plug flow device. The COBC could be considered as a cascade of MSMPR crystallizers in series or a plug-flow type crystallizer with dispersion terms $D_{n} \partial n^{2} / \partial z^{2}$ and $D_{c} \partial n \mathbf{C}^{2} / \partial z^{2}$ added to eqs.(1) and (2) for dynamic simulation, or to eqs.(8) and (9) for steady-state modeling, respectively. Here $D_{n}$ and $D_{c}$ are dispersion coefficients for crystals and liquid solution, respectively. Both the number of stages in a cascaded MSMPR crystallizer and the dispersion coefficients could be estimated from experimental residence time distributions of a $\mathrm{COBC}$, which will be a future development in our work. 


\section{OPTIMIZATION OF MSMA PLUG-FLOW CRYSTALLIZER}

In a similar way to a cascaded multi-stage continuous MSMPR crystallizer $^{11,12,15}$, several segments of tubular crystallizer can be joined together with temperature control applied to each segment and / or additions of anti-solvent or fresh solution injected between any two consecutive segments in order to regulate the main solute concentration and supersaturation along the tube, as shown in Figure 1. In the present study, each segment is regarded as an individual plug-flow crystallizer, which forms a part of the multi-segment, multi-addition plug-flow crystallizer. The current study considers the addition of anti-solvent to create the supersaturation profile.

In terms of the dynamic simulation of the MSMA-PFC, the outlet slurry of one PFC segment is assumed to mix instantly with the added fresh solution or anti-solvent stream under an ideal mixing rule. Both solvent and anti-solvent have a low viscosity and are fully miscible with each other; moreover, the system does not nucleate very rapidly and hence the assumption of instantaneous mixing may be justified. In practice, if mixing of the anti-solvent stream with the slurry is limiting, then a high addition velocity or static mixers inside the tube can be applied to intensify the mixing conditions ${ }^{1}$. Hence the crystal number probability density function $n$ and the solute concentrations $\mathbf{C}$ at the outlet are diluted accordingly and thus need to be updated and set as inlet boundary conditions for the next PFC segment, viz., eqs.(4) and (5). Similar calculations also apply to the steady-state model. For more information on this, readers are referred to the work by Ridder et al. $^{24}$

Previously, Alvarez and Myerson ${ }^{1}$ reported a combination of four equal-length tubular units (length: $4 \times 0.6 \mathrm{~m}$; diameter: $1.27 \mathrm{~cm}$ ), with empirically designed distribution of anti-solvent among the four units, for example, $50 \%, 50 \%, 0 \%, 0 \%$, and with a fixed amount of total anti- 
solvent addition. Ridder et $a .^{24}$ optimized the distribution of anti-solvent for a number of equally-spaced injection points, where up to 15 injection points were considered for a $50 \mathrm{~m}$ long tube, requiring a unit segment length of 50/15 m. However, the segmentation of their design method is only optimal for a specific crystallization system; it may not be optimal for other systems and thus their multi-segment design is not as versatile as generally demanded by the pharmaceutical industries. Furthermore, depending on the relative competitiveness of crystal growth rate and nucleation rate, varying ranges of supersaturation along the tubular crystallizer may be required to achieve the best product attributes. Hence, without resorting to optimize too many equally-spaced injections, it is more desirable and useful to optimize both the locations and distribution of a limited number of anti-solvent or fresh solution injections to achieve better control of supersaturation. This new method of optimization of the continuous MSMA-PFC provides the same level of operating flexibility as a batch crystallizer in which anti-solvent can be added at any time and hence should result in better control or product quality attributes.

To sum up, a practical multi-segment multi-addition tubular crystallizer should have the concept of a modular design, which comprises standardized unit segments, for example, a module of $0.6 \mathrm{~m}$ long, as studied by Alvarez and Myerson ${ }^{1}$. Then for a tubular crystallizer made up of $N$ segments (hence with $N$ possible addition points), the locations and distribution of antisolvent/fresh solution additions for a total number of $m(m \leq N)$ injections points could be optimized to obtain better product qualities. At the current stage, the optimization of only the anti-solvent addition is considered, as shown in eqs.(15) to (18) below; optimization of both antisolvent and fresh solution additions (and temperature) would be straightforward and can be considered in future work. The optimization problem can be stated as to maximize the product qualities (e.g., mean crystal size, product yield, etc.) $\mathbf{P}$ at the outlet of the final segment $Z_{N}$ 


$$
\underset{\mathbf{U}, \mathbf{A}}{\operatorname{MAX}}(\mathbf{P})_{Z_{N}}
$$

subject to a number of linear and nonlinear constraints on the product qualities $\mathbf{P}$, represented by eq.(16)

$$
f(\mathbf{P})_{Z_{N}} \leq 0
$$

The optimization represented by eq.(15) involves

(i) changing the location of $m$ anti-solvent additions; in eq.(17), $\boldsymbol{U}$ represents an integer list of index numbers of the addition points; there is always an anti-solvent addition in segment 1 and the remaining $m-1$ additions may occur at the start of segments between 2 and $N$;

(ii) changing the mass fraction $x_{i}$ of the $i^{\text {th }}$ anti-solvent addition, where $i=1 \ldots m$, as represented by the list in $\mathbf{A}$. The total flow rate of anti-solvent added in each case is treated as fixed.

$$
\begin{gathered}
\mathbf{U}=\left[u_{1}, u_{2}, u_{3}, \ldots, u_{m}\right] \text { where } u_{1}=1 \\
\mathbf{A}=\left[x_{1}, x_{2}, \ldots, x_{m}\right] \text { where } \sum_{i=1}^{m} x_{i}=1
\end{gathered}
$$

Under the proposed design and optimization framework, it is convenient to consider a MSMA-PFC with a desired total length assembled from a fixed number of unit segments ${ }^{1}$ and also with an optimized anti-solvent addition. Thus it is possible to make the MSMA-PFC flexible and efficient for a variety of crystallization systems. As expected, when a large number of injections are chosen $(m \sim N)$, there would be only marginal benefits over the equally-spaced 
injections; hence, the list $\mathbf{U}$ of injection positions can be fixed and only the distribution vector $\mathbf{A}$ is allowed to vary in the optimization problem.

The above optimization problem of eqs.(15) to (18) is a mixed integer non-linear programming problem (MINLP) and can be solved by the genetic algorithm with an integer constraint "intcon" in MATLAB. The genetic algorithm is an adaptive heuristic search method based on the evolutionary ideas of natural selection and genetics and is capable of searching a large or multi-modal state-space, offering significant benefits over more deterministic optimization techniques.

Multi-objective optimizations have been widely applied to the crystallization process, e.g. to observe the Pareto front among several key performance indices, such as the volume-based mean crystal size, coefficient of variation (CV), yield, or the ratio of seeded crystals over nucleated crystals $^{24,31,32}$. In the current application, the residence time distribution is narrow in a plug-flow crystallizer and should not contribute to a broadening of the CSD through back-mixing effects. Instead an increase in the $\mathrm{CV}$ is more likely to result from multiple nucleation events along the tube, triggered by anti-solvent additions and potentially leading to a multi-modal CSD. Multiobjective optimization of the mean crystal size and the $\mathrm{CV}$ is possible; however, here the objective function was simply written in terms of maximizing the mean particle size, but adding the constraints that (i) a minimum yield had to be obtained and (ii) the CV had to be less than 0.30, ensuring a relatively narrow CSD. This approach is intended to minimize the effects of multiple nucleation events and to provide a narrow distribution of large crystals suitable for secondary manufacturing processes, e.g. filtration or continuous mixing ${ }^{33}$. Extensions of the approach to other (multi-) objective functions would be straightforward to implement, but the formulation proposed here is sufficient to demonstrate the ability to design optimized processes. 
Therefore, in this study, only the mean crystal size $L_{43}$ is maximized with constraints imposed both on CV and product yield (as shown in Table 1). 


\section{RESULTS AND DISCUSSION}

\section{Tubular Crystallizer Design}

To demonstrate the proposed design and optimization framework for the MSMA-PFC, a unseeded anti-solvent crystallization system of paracetamol in an acetone (solvent) and water (anti-solvent) mixture at a constant temperature of $16{ }^{\circ} \mathrm{C}$ is investigated using numerical simulation. The feed solution of paracetamol is first saturated at a water mass fraction of $60 \%$ ( $0.1917 \mathrm{~g}$ solute/g solvents) and then injected into a $72 \mathrm{~m}$ long tube, which consists of 120 segments. Each modular segment is $0.6 \mathrm{~m}$ in length and $1.27 \mathrm{~cm}$ in diameter ${ }^{1}$. Addition of antisolvent is also assumed to be possible only in the inlet of each modular segment and as described above is assumed to mix instantly with the slurry inside the tube. A total flow rate of $50 \mathrm{ml} / \mathrm{min}$ of fresh saturated solution is fed to the first segment, and a total flow rate of $25 \mathrm{ml} / \mathrm{min}$ of water as anti-solvent is injected along the MSMA-PFC. The mean residence time is assumed to be fixed at $120 \mathrm{~min}^{\mathrm{a}}$, similar to the typical semi-batch crystallization process reported by Woo et $a l^{34}$, in which the solubility model and crystallization kinetics equations (minor typo errors therein are corrected) are presented as follows for easy reference.

$$
\begin{gathered}
C^{*}(\mathrm{~kg} \text { solute } / \mathrm{kg} \text { solvents })=1.302 \times 10^{-6} w^{3}-1.882 \times 10^{-4} w^{2}+ \\
2.237 \times 10^{-4} w+5.746 \times 10^{-1} \\
\Delta C(\mathrm{~kg} \text { solute } / \mathrm{kg} \text { solvents })=C-C^{*} \\
B\left(\# / \mathrm{m}^{3} / \mathrm{s}\right)=k_{b} \Delta C^{b}
\end{gathered}
$$

\footnotetext{
a The mean flow rate $\bar{v}_{z}$ in each modular segment is different due to the anti-solvent addition, which affects the mean residence time in each segment.
} 


$$
\begin{gathered}
k_{b}=4.338 \times 10^{58} \exp (-1.374 w) \\
b=1.997 \times 10^{-3} w^{2}-6.237 \times 10^{-1} w+4.042 \times 10^{1} \\
G(\mathrm{~m} / \mathrm{s})=k_{g} \Delta C^{g} \\
k_{g}=-9.6300 \times 10^{-11} w^{3}+3.3558 \times 10^{-8} w^{2} \\
-1.2606 \times 10^{-6} w+3.6852 \times 10^{-5} \\
g=-1.108 \times 10^{-4} w^{2}+1.024 \times 10^{-2} w+1.427
\end{gathered}
$$

where $w$ is the mass percentage of anti-solvent in the solvent mixture; $\Delta C$ is the absolute supersaturation. Both the crystal growth rate $G$ and the nucleation rate $B$ are dependent on supersaturation and anti-solvent mass fraction; as previously mentioned the anti-solvent mass fraction has a complex effect on supersaturation, which make the control and optimization of product qualities very challenging. For example, in a semi-batch crystallizer system ${ }^{34}$, the antisolvent flowrate was required to increase exponentially to maintain a constant trade-off of crystal growth and nucleation (so-called C-control ${ }^{34}$ for a semi-batch process).

The selected crystallization kinetics was taken from batch crystallization experiments by Woo et $a l .{ }^{34}$, obtained through parameter estimation. They are used for illustrative purposes only and are not intended to perfectly represent the crystallization behavior in a continuous plug-flow crystallizer. The fluid mechanics in these two devices are not comparable, and hence phenomena such as the secondary nucleation processes induced by a moving impeller in a batch crystallizer are unlikely to the same as in plug-flow crystallizer, through particle-wall, or particle-particle collisions. Realistic nucleation models should be included in design calculations for continuous crystallizers, particularly given the sensitivity of the optimization to the detail of the nucleation 
kinetics $^{24}$. For the design of real crystallization processes, parameter estimation to obtain the rate laws relevant to the fluid flow in the process equipment should be conducted as part of a preliminary experimental study of a PFC design, but is not considered as part of the current work.

\section{Optimisation of Antisolvent Addition}

As discussed previously, a computationally efficient steady-state model of MSMA-PFC using MOM is employed here for the optimal design problem of the anti-solvent additions. The optimal results are then re-simulated by the FVM to capture the full CSD development in the tubular crystallizer. This avoids the difficulty of trying to reconstruct the full CSD from its moments and reduces the computational time for the optimization; it is important here, because there is a possibility to obtain multi-modal size distributions, which may not be evident from the moments alone.

Practically it would be infeasible to use a large number of injection points. The performance of the MSMA-PFC, was studied for up 6 injection points; the first is always at the entry to the first segment and the remainders are selected from the following 119 segments. Three case studies are considered:

- Case 1 , serves as an unoptimized bench mark, and considers equally-spaced injection points with equally distributed anti-solvent addition, as studied by Alvarez and Myerson ${ }^{1}$;

- Case 2 considers also the equally-spaced injection points, but with optimized distribution of anti-solvent addition, as studied by Ridder et $a l^{24}$;

- Case 3 optimizes both the location of the addition points and the distribution of antisolvent 
For Cases 2 and 3, the objective was to maximize $L_{43}$, whilst maintaining $C V \leq 0.30$ and $C\left(Z_{N}\right) \leq 0.806 \mathrm{~kg} / \mathrm{kg}$, i.e. without broadening the crystal size distribution too much and with an acceptable yield. For an unseeded anti-solvent crystallization in this MSMA-PFC, the width of the CSD is mainly determined by the magnitudes of multiple nucleation events. Paracetamol in acetone is a relatively slow growing system and is dominated by nucleation; hence maximizing the mean crystal size under a minimum yield constraint, will automatically limit these multiple nucleation events.

The genetic algorithm for MINLP problem in MATLAB 2013b was implemented for the optimization problems of Cases 2 and 3. To cope with the stochastic nature of the genetic algorithm, population sizes of 30,60, 100 and 200 were implemented together with maximum generations of 150 for each optimization scenario of Cases 2 and 3; the best solution of each was then chosen as the final optimal result.

The final optimization results of the case studies are summarized in Table 1. For example, in Case 2 of the MSMA-PFC with totally four injection points $(m=4)$, the location index $\mathbf{U}=\left[\begin{array}{ll}1 & 31\end{array}\right.$ 6191 ] means the third anti-solvent addition is located at the $61^{\text {st }}$ segment, or axial position of $z=$ $(61-1) \times 0.60 \mathrm{~m}=36.0 \mathrm{~m}$. The corresponding anti-solvent feed distribution is given by $\mathbf{A}=$ $[0.242,0.025,0.733,0.001]$ and shows, for example, that the flow rate of the third anti-solvent addition was $0.733 \times 25 \mathrm{ml} / \mathrm{min}=18.3 \mathrm{ml} / \mathrm{min}$. Comparisons of the three case studies for four injection points in the MSMA-PFC are shown in Figures 2 to 4 for paracetamol concentration, evolution of crystal number density, and the volume-based CSD profiles at specific axial positions, respectively. 
Figure 2 shows that all the three cases maintain a certain level of supersaturation, which reduces between each addition; the first anti-solvent addition at the inlet of the crystallizer produces the first burst of nuclei, which passes through the following PFC segments for further growth and finally contributes to the generation of the majority of the large particles at the outlet, as is illustrated in Figures 3 and 4. After the second addition, the equally-distributed addition in Case 1 creates a large supersaturation, which results in the second peak in the broadened CSD (see Figure 4: case 1 for $z>18 \mathrm{~m}$ ). Case 2 reduces the amount of anti-solvent addition at the same position compared to Case 1 at $z=18 \mathrm{~m}$; this extends the supersaturation level achieved in the previous segment so that before the third addition (where a large amount of anti-solvent is added) there are enough medium-size crystals for growth to compete with the nucleation effect and thereby consume the supersaturation. In such a way, there is a significant increase of the final mean crystal size from $370 \mu \mathrm{m}$ of Case 1 to $499 \mu \mathrm{m}$ of Case 2 as shown in Table 1 ; the CV was constrained to be $<0.30$. Interestingly, due to the limited residence time for crystal growth in the final segment, there are only small amounts of anti-solvent added from the last injection points close to the end of PFC for 4, 5 and 6 addition points; see Case 2 (see Table 1). Figure 3 also shows that there is very little change in the CSD in the last few segments of the MSMAPFC. Hence, when the total number of injection points is limited by practical constraints, the optimal locations of the injection points are rather important. With this in mind, in Case 3 both the locations and the distribution of the anti-solvent additions are optimized and, as a result, a nearly constant supersaturation level is maintained up to the fourth addition at the $63^{\text {rd }}$ segment, after which a large supersaturation level is also generated, analogous to that in Case 2. A further increase in the mean crystal size with a lower $\mathrm{CV}$ is obtained for Case 3 compared to Case 2 as shown in Table 1 and Figures 3 and 4. The latter indicates the strategy employed in Case 3 is 
more successful in controlling the nucleation rate throughout the whole tube, giving the largest mean crystals sizes and maintaining a CV well below the constraint of 0.30 .

The effect of the total number of injection points on the mean crystal size at the exit of the MSMA-PFC is summarized in Table 1 and also depicted in Figure 5; Case 3 always produces the largest mean crystal size and increasing the number of injection points beyond four only contributes marginally to improve the performance of the MSMA-PFC. Most importantly, consistent optimal locations for additions were found for Case 3, where nearly all of the antisolvent additions are added in the first half of the crystallizer tube. In contrast, variations in the optimization results were obtained for equally-spaced injection points of Cases 1 and 2, which were also reported by Ridder $e t a l^{24}$. In Cases 1 and 2 the anti-solvent is added more uniformly along the length of the crystallizer, as the number of injection points increases; however, this strategy fails to provide enough anti-solvent addition in the first half of the tube. Thus results of Figures 3 to 5 show that for an MSMA-PFC, an optimization of both the location and amount of anti-solvent additions should be taken into account to achieve the best flexible, efficient and cost-effective design.

For further comparison, the batch crystallization process with an optimal C-control strategy (a methodology to manipulate the supersaturation to trade-off the nucleation and crystal growth rates), using a seed (mean size $220 \mu \mathrm{m}$ ) achieved a final crystal mean size of $556 \mu \mathrm{m}$ for a batch time of $120 \mathrm{~min}$ in ref. 34. Therefore, the proposed design and optimization framework of MSMA-PFC, producing final crystals with good quality, shows the potential to implement an innovative continuous crystallizer design to replace existing batch crystallization processes. 
In terms of the robustness analysis of the optimization results, Ridder et ll $^{24,}{ }^{35}$ have thoroughly illustrated that, for an unseeded anti-solvent crystallization in a MSMA-PFC, the final product qualities are rather sensitive to uncertainties in the nucleation kinetics and the first anti-solvent addition rate. Obviously, the nucleation kinetics plays a decisive role in an unseeded crystallization, as they determine the total number of crystals generated. Therefore, the first antisolvent addition is important since it generates the supersaturation which is responsible for the largest nucleation rates. For sufficiently long tubes, the nascent crystals continue to grow until the supersaturation is exhausted, which leads to a reduced sensitivity of the optimization results to crystal growth kinetics and the subsequent anti-solvent additions. Similar trends are also found in the current work. For example, comparisons of the robustness of the optimal results $(m=4)$ in Table 1 under uncertainties in the nucleation kinetic parameter $k_{b}$ are shown in Figure 6, where $k_{b}$ is multiplied by a parameter $k_{u c}$ to represent the uncertainty. It is found that similar sensitivities are obtained for Cases 2 and 3, as mentioned above, although the proposed optimization framework maintains a better performance over its counterparts. Therefore, it is much more desirable to reduce these sensitivities by introducing proper seeding techniques or an elaborate design of a nucleator in the first PFC segment, which is an ongoing project in our group.

\section{Dynamic Simulation}

A dynamic simulation of the above MSMA-PFC design was conducted with the optimized four injection locations and anti-solvent distributions of Case 3, as shown in Table 1. Firstly, the MSMA-PFC is assumed to start up by injections of anti-solvent into the crystallizer according to the optimal results of anti-solvent addition, by which the crystallizer can be first filled and purged using the less expensive anti-solvent (water). Then the fresh feed saturated solution, with 
a constant flow rate of $50 \mathrm{ml} / \mathrm{min}$, is injected and mixed with the first anti-solvent addition at the inlet of first PFC segment.

The evolution of the paracetamol concentration along the crystallizer axial is depicted in Figure 7. The discontinuities in the concentration are due to the dilution effect of the anti-solvent additions. Apart from the transient response at the inlet for the first few minutes, the start-up of the MSMA-PFC is relatively smooth compared to a stirred-tank design (which typically requires more than four mean residence time to reach steady-state), approaching the steady-state in just after the first mean residence time. The observed transient response at the inlet is due to the high supersaturation generated by the instant mixing of fresh solution with the first anti-solvent addition of $0.241 \times 25 \mathrm{ml} / \mathrm{min}$, leading to a relative large nucleation effect and its propagation into the following segments, as is more clearly shown in Figures 8 and 9. The initial peak at solute concentration profile for $\mathrm{z}=0.0^{+} \mathrm{m}$ is due to the fast depletion of solute by spontaneous nucleation after the generation of large supersaturation at the inlet. After that event, the nucleation effect is reduced (see Figure 9 for $z=0.0^{+}$) as the concentration remains nearly constant and reaches its steady-state; the already generated nuclei in the inlet then serve as the seeding crystals in the remaining sections of the crystallizer.

The large numbers of nuclei generated at the entry, pass through the following PFC segments, consuming supersaturation through growth and resulting in an initially slightly lower concentration than at the steady-state condition, as shown in Figure 8 for different tube locations. Figure 9 shows that the effects of this initial burst of nuclei quickly vanish from the dynamic evolution of the CSD inside the tube. Although this high supersaturation only occurs at the beginning of the start-up process, its effect on the crystal size distribution could be important in practice, causing crash nucleation and fouling at the inlet ${ }^{35}$. The use of a dynamic simulation 
illustrates the problems that might occur on start-up and allows design of a mitigation strategy, e.g. to initially provide some seeding into the fresh feed saturated solution at the beginning of the start-up process and then move more slowly back to an unseeded operation. For example, a 2.0\% seeded fresh slurry was used to start up the MSMA-PFC with optimal anti-solvent distribution of Case $3(m=4)$, as shown in Figures 10 and 11 for the paracetamol concentration and CSD evolution at the inlet, respectively. Here, a log-normal seed crystal size distribution with a mean size of $60 \mu \mathrm{m}$ and a standard deviation of 1.5 was continuously seeded for 60 minutes. Comparing to the unseeded start-up in Figures 7 and 9 (for $\mathrm{z}=0.0^{+}$), the seeded crystallization over the first 60 minutes decreased the paracetamol concentration significantly, while initializing the crystallization at the inlet. After stopping the seed feed addition, the process slowly resumed to a high concentration at the inlet and also reached the same optimal steady state as Case 3 ( $m=$ 4), without causing an initial large burst of nucleation.

In summary, it is obvious that the MSMA-PFC, by optimized process design, shows the advantages of a quick start-up and potentially simplified process control needed to reach a steady-state operation, compared to that observed in cascaded multi-stage MSMPR crystallizers $^{16,36}$. 


\section{CONCLUSIONS AND FUTURE WORK}

The multi-segment, multi-addition plug-flow crystallizer (MSMA-PFC) has shown potential benefits for the design of optimized continuous crystallization processes, which can replace existing batch operations. The current work has extended the previous work in mathematical modeling, design, and optimization of an MSMA-PFC, proposing a conceptual design based on a number of standardized modular units, an optimization framework for finding the best locations and amounts of anti-solvent additions and a dynamic simulation to study its start-up. Improvements to the previous optimization frameworks reported in the literature by Alvarez and Myerson ${ }^{1}$ and Ridder et $a l .^{24}$ were illustrated, showing that larger mean crystal sizes could be obtained, with the CV maintained below a target level. The proposed design framework avoids the formation of multiple large nucleation events, which give rise to multi-modal and broad size distributions of the crystal product. The method is quite general and can be adapted to take into account different definitions of the process objective and to target a variety of product quality attributes. Nevertheless, the simulations require input in the form of kinetic rate laws, which should be obtained from experiments conducted under the relevant flow conditions. Future work will consider the effects of initial seeding at the inlet, additions of fresh solution along the tube, and a temperature profile for a combined cooling and anti-solvent crystallization process. Further extensions of the plug-flow crystallizer to a continuous oscillatory baffled crystallizer (COBC) with some axial dispersion are also under investigation. 


\section{AUTHOR INFORMATION}

\section{Author Contributions}

The manuscript was written through contributions of all authors. All authors have given approval to the final version of the manuscript.

\section{Funding Sources}

Engineering and Physics Science Research Council of United Kingdom (UK EPSRC $\mathrm{EP} / \mathrm{K} 014250 / 1)$

\section{ACKNOWLEDGMENT}

This work was performed within the UK EPSRC funded project (EP/K014250/1) 'Intelligent Decision Support and Control Technologies for Continuous Manufacturing and Crystallization of Pharmaceuticals and Fine Chemicals' (ICT-CMAC). The authors would like to acknowledge financial support from EPSRC, AstraZeneca and GSK. The authors are also grateful for useful discussions with industrial partners from AstraZeneca, GlaxoSmithKline, Mettler-Toledo, Perceptive Engineering and Process Systems Enterprise. 


\author{
ABBREVIATIONS \\ ATR-FTIR, attenuated total reflectance Fourier-transform infrared spectroscopy; \\ COBC, continuous oscillatory baffled crystallizer; \\ CSD, crystal size distribution; \\ $\mathrm{CV}$, coefficient of variation; \\ FBRM, focused-beam reflectance measurement; \\ FVM, finite volume method; \\ MINLP, mixed integer nonlinear programming problem; \\ MOM, method of moments; \\ MSMA, multi-segment multi-addition; \\ MSMPR, mixed-suspension mixed-product-removal; \\ ODE, ordinary differential equation; \\ PAT, process analytical technology; \\ PDE, partial differential equation; \\ PFC, plug-flow crystallizer; \\ PSE, process systems engineering; \\ PVM, particle vision measurement; \\ SDC, simultaneous design and control.
}




\section{REFERENCES}

(1) Alvarez AJ, Myerson AS. Crvst. Growth Des. 2010; 10:2219-2228.

(2) Chen J, Sarma B, Evans JMB, Myerson AS. Crvst. Growth Des. 2011; 11:887-895.

(3) Majumder A, Nagy ZK. AIChEJ. 2013; 59:4582-4594.

(4) Plumb K. Chem Eng.Res. Des. 2005; 83:730-738.

(5) Reklaitis GV, Khinast J, Muzzio F. Chem. Eng. Sci. 2010; 65: iv-vii.

(6) Kessel M. Nat. Biotechnol. 2011; 29:27-33.

(7) Mascia S, Heider PL, Zhang H, Lakerveld R, Benyahia B, Barton PI, Braatz RD, Cooney CL, Evans J, Jamison TF, Jensen KF, Myerson AS, Trout BL. Angew. Chem.Int.Ed. 2013; $52: 12359-12363$.

(8) Buchholz S. Chem. Eng Process. 2010; 49:993-995.

(9) Aksu B, De Beer T, Folestad S, Ketolainen J, Linden H, Lopes JA, de Matas M, Oostra W, Rantanen J, Weimer M. Eur.J.Pharm.Sci. 2012; 47:402-405.

(10) Banholzer WF, Jones ME. AIChE J. 2013; 59:2708-2720.

(11) Griffin DW, Mellichamp DA, Doherty MF. Chem.Eng.Sci. 2010; 65:5770-5780.

(12) Alvarez AJ, Singh A, Myerson AS. Crvst. Growth Des. 2011; 11:4392-4400.

(13) Quon JL, Zhang H, Alvarez A, Evans J, Myerson AS, Trout BL. Crust. Growth Des. 2012; $12: 3036-3044$

(14) Zhang H, Quon J, Alvarez AJ, Evans J, Myerson AS, Trout B. Org. Process Res. Dev. 2012; 16:915-924.

(15) Sen M, Rogers A, Singh R, Chaudhury A, John J, Ierapetritou MG, Ramachandran R. Chem.Eng.Sci. 2013; 102:56-66.

(16) Su Q, Nagy ZK, Rielly CD. Chem. Eng Process. 2015; 89:41-53. 
(17) Lawton S, Steele G, Shering P, Zhao L, Laird I, Ni XW. Org Process Res. Dev. 2009; 13:1357-1363.

(18) Eder RJP, Radl S, Schmitt E, Innerhofer S, Maier M, Gruber-Woelfler H, Khinast JG. Crvst. Growth Des. 2010; 10:2247-2257.

(19) Eder RJP, Schmitt EK, Grill J, Radl S, Gruber-Woelfler H, Khinast JG. Crvst. Res. Technol. 2011; 46:227-237.

(20) Ferguson S, Morris G, Hao H, Barrett M, Glennon B. Chem.Eng.Sci. 2012; 77:105-111.

(21) Zhou L, Su M, Benyahia B, Singh A, Barton PI, Trout BL, Myerson AS, Braatz RD. AIChEJ. 2013;59:1308-1321.

(22) Lakerveld R, Kramer HJM, Stankiewicz AI, Grievink J. Chem. Eng. Process. 2010; 49:979-991.

(23) Vetter T, Burcham CL, Doherty MF. Chem.Eng.Sci. 2014; 106:167-180.

(24) Ridder BJ, Majumder A, Nagy ZK. Ind.Eng.Chem.Res. 2014; 53:4387-4397.

(25) Kwon JS, Nayhouse M, Orkoulas G, Christofides PD. Chem.Eng.Sci. 2014;119:30-39.

(26) Byrn S, Futran M, Thomas H, Jayjock E, Maron N, Meyer RF, Myerson AS, Thien MP, Trout BL. In: International Symposium on Continuous Manufacturing of Pharmaceuticals. May 20-21, 2014.

(27) Leuenberger H. Eur. J. Pharm. Biopharm. 2001; 52:289-296.

(28) Su QL, Chiu MS, Braatz RD. AIChEJ. 2014; 60:2828-2838.

(29) Qamar S, Elsner MP, Angelov IA, Warnecke G, Seidel-Morgenstern A. Comput. Chem. Eng. 2006; 30:1119-1131.

(30) Mesbah A, Kramer HJM, Huesman AEM, Van den Hof PMJ. Chem. Eng. Sci. 2009; 64:4262-4277. 
(31) Deb K, Pratap A, Agarwal S, Meyarivan T. LEEE Trans.Evol.Comput. 2002; 6:182-197.

(32) Su QL, Braatz RD, Chiu MS. L.Process Control. 2014; 24:415-421.

(33) Abel MJ. Massachusetts Institute of Technology, PhD Thesis, 2009.

(34) Woo XY, Nagy ZK, Tan RBH, Braatz RD. Crvst. Growth Des. 2009; 9:182-191.

(35) Ridder BJ, Majumder A, Nagy ZK. In: Proceedings of the American Control Conference (ACC 2014), IEEE Press, Piscataway, NY, Seattle, USA, 2014.

(36) Yang Y, Nagy ZK. Chem.Eng.SCi. 2015; 127:362-373. 


\section{FIGURES AND CAPTIONS}

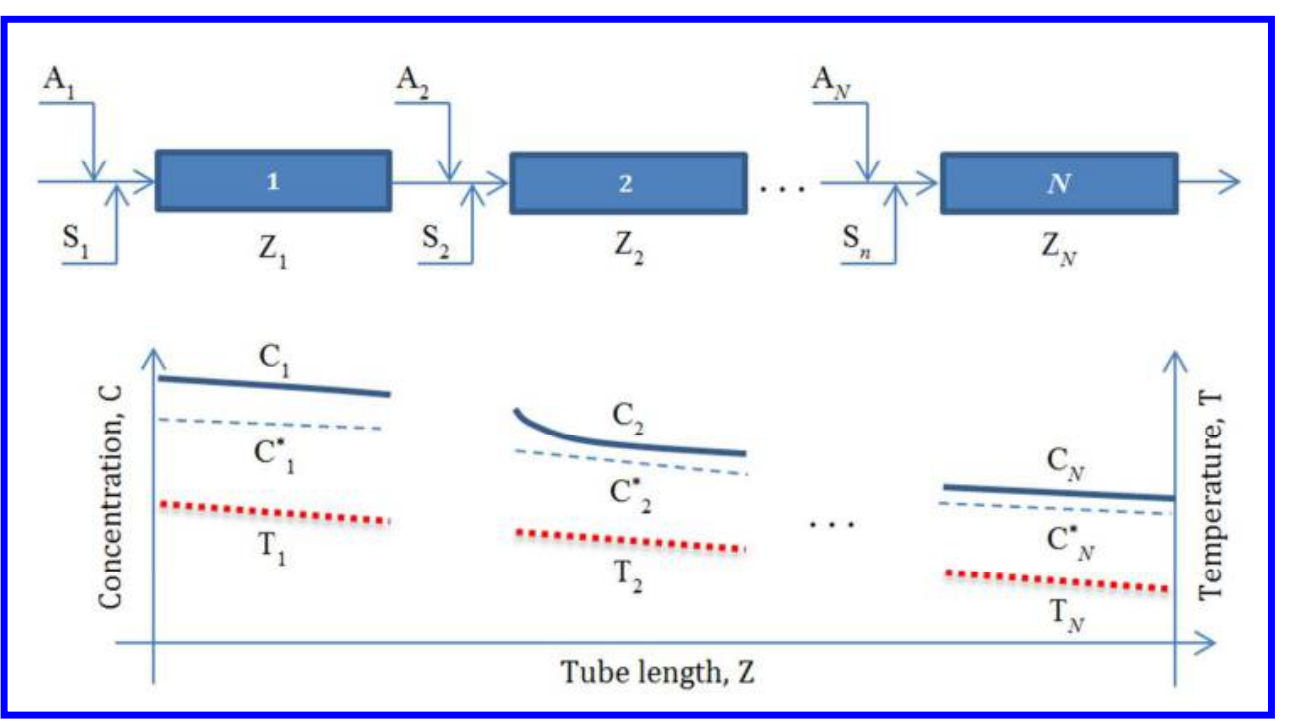

Figure 1. Schematic of a multi-segment multi-addition plug-flow crystallizer. $\left(\mathrm{A}_{i}\right.$ : anti-solvent addition for the $i^{\text {th }}$ segment; $S_{i}$ : fresh solution addition; $Z_{i}$ : tube length; $C_{i}$ : main solute concentration; $C_{i}^{*}$ : main solute solubility in $i^{\text {th }}$ segment; $T_{i}$ : temperature; $N$ : total number of segments.) 


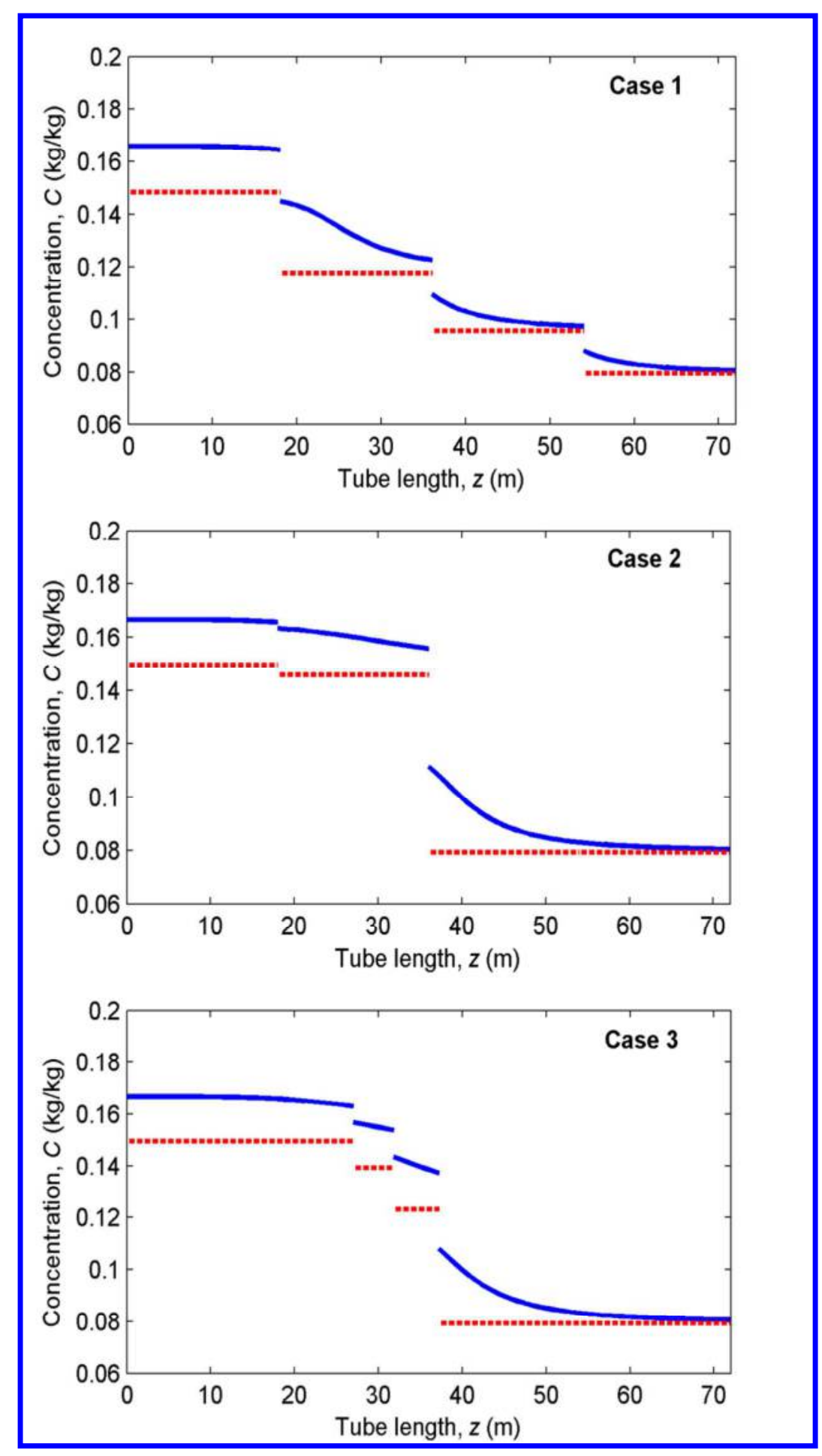

Figure 2. Optimization results of concentrations for four injection points in MSMA-PFC. (Solid line: solute concentration; dashed line: solute solubility.) 

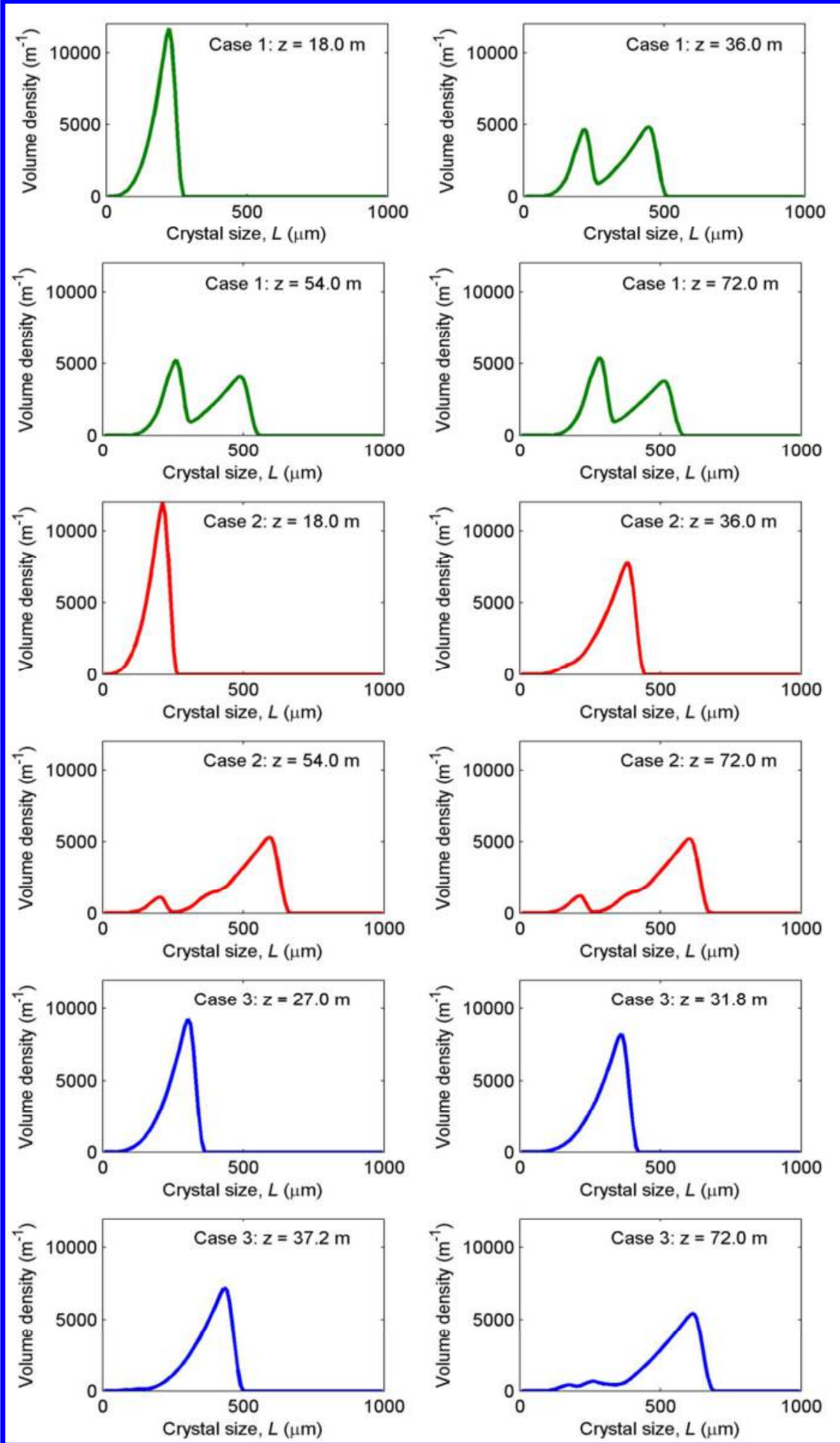

Figure 4. Optimization results of volume-based CSD for four injection points in MSMA-PFC

(Upper four: Case 1; center four: Case 2; Lower four: Case 3). 


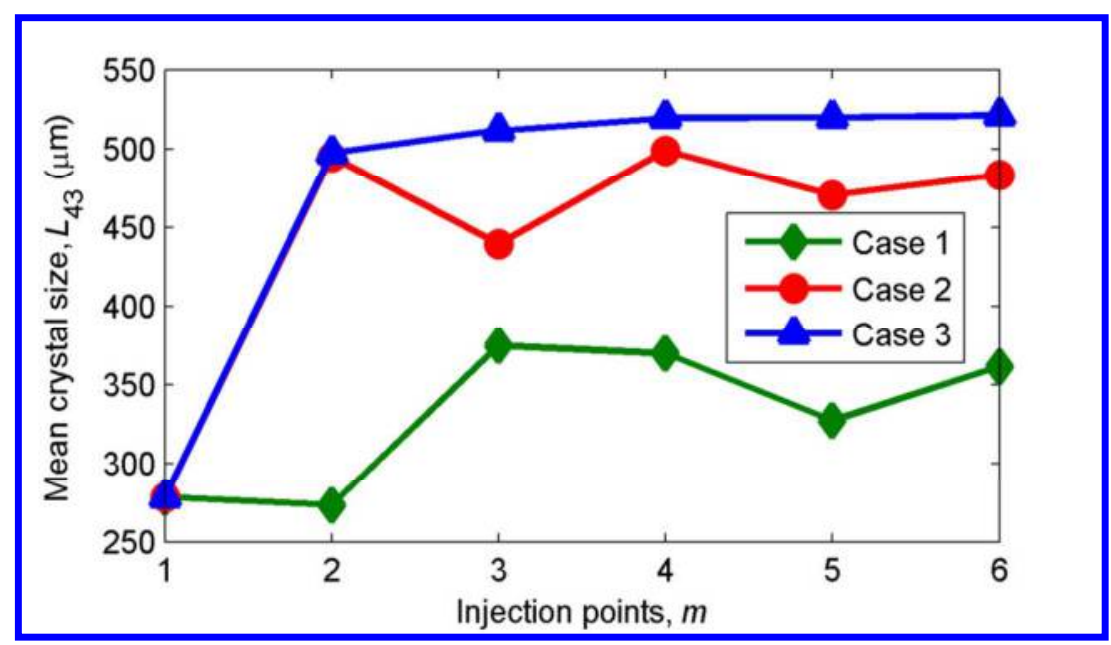

Figure 5. Effect of the number of injection points on optimization results of MSMA-PFC.

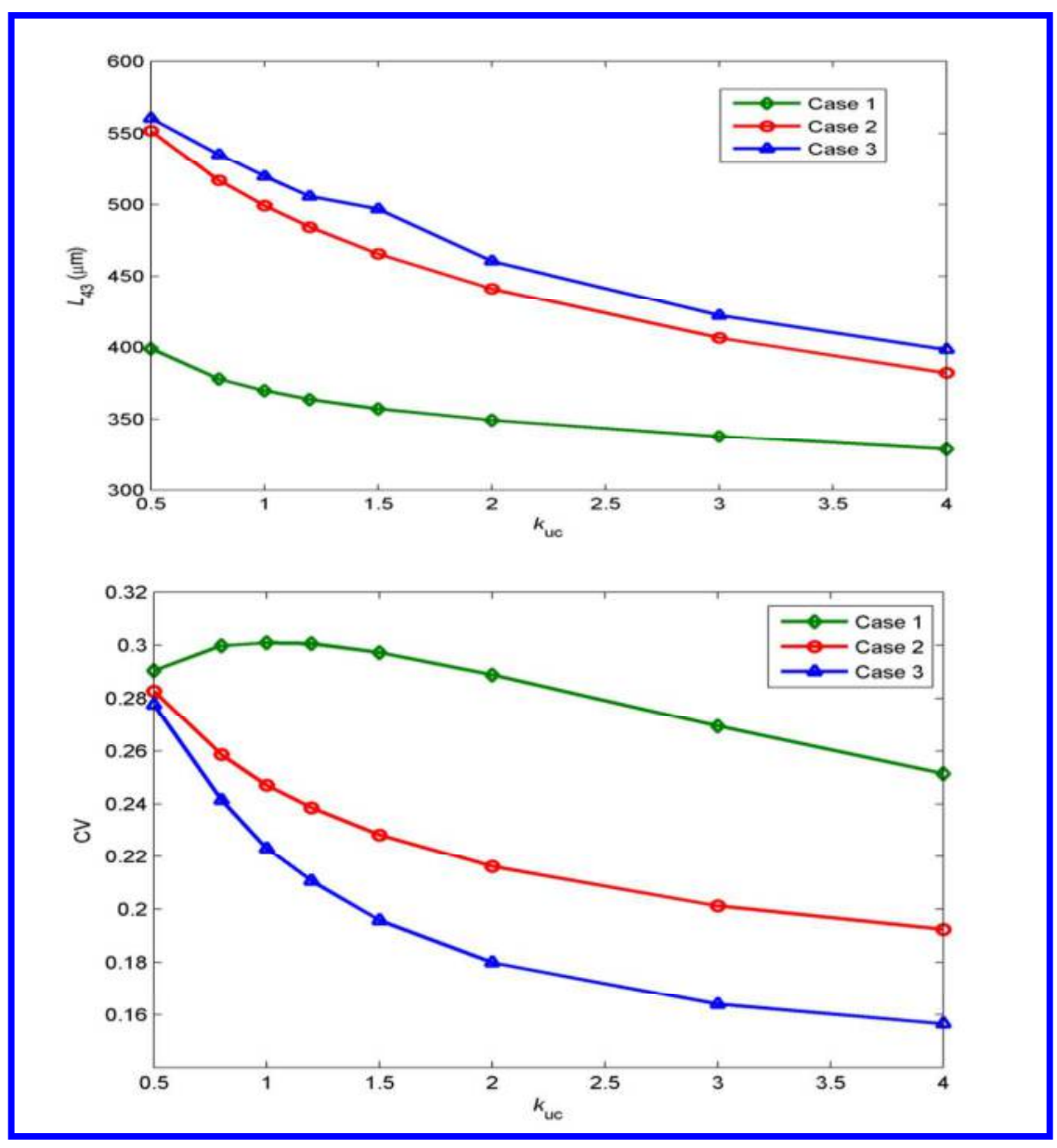

Figure 6. Robustness analyses of optimization results $(m=4)$ of MSMA-PFC with regard to nucleation uncertainties. 


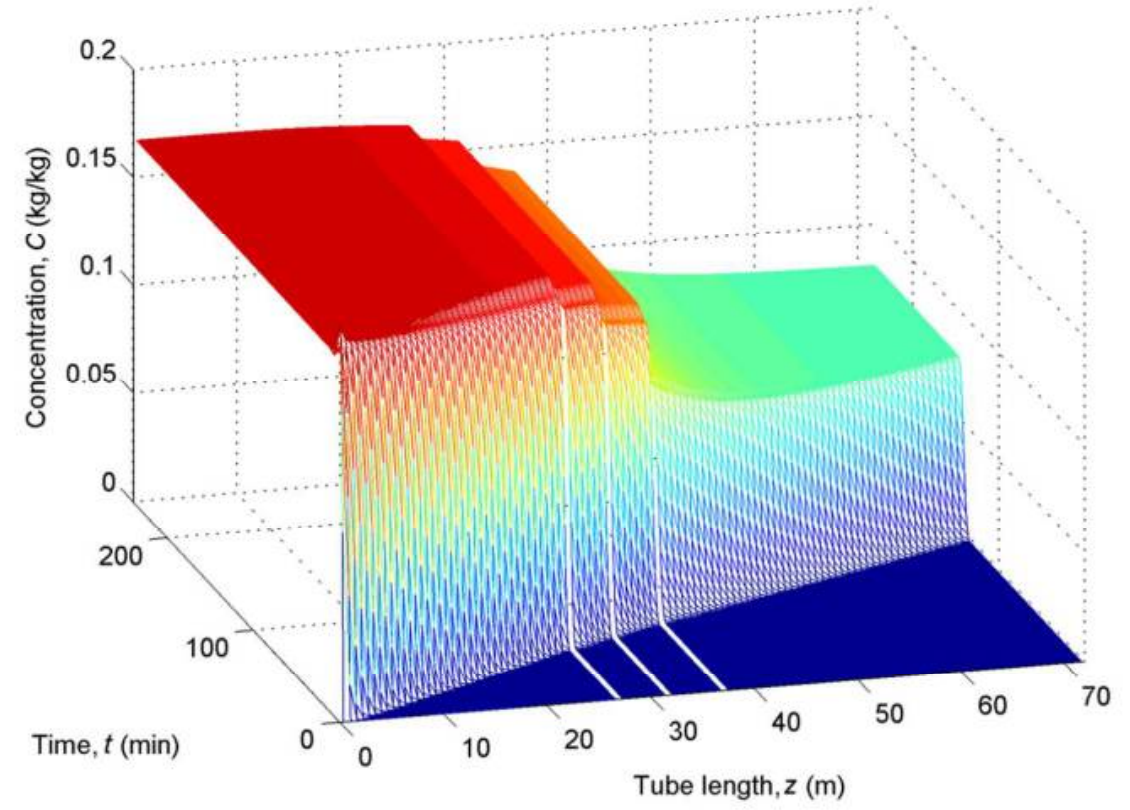

Figure 7. Dynamic simulation of main solute concentration in MSMA-PFC for Case $3(m=4)$.

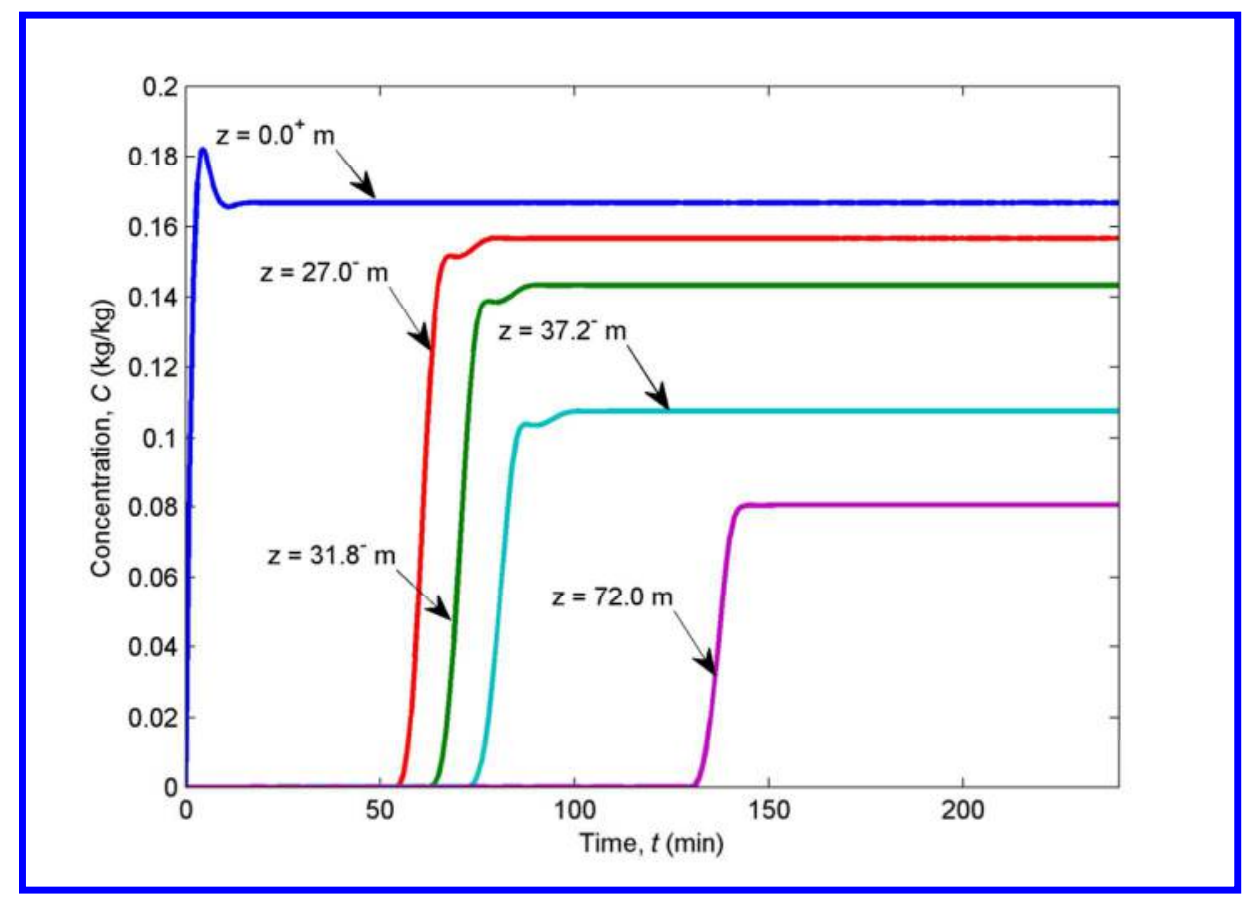

Figure 8. Dynamic simulation of main solute concentration at different tube locations of Case 3

$$
(m=4)(+: \text { after anti-solvent addition; -: before anti-solvent addition at addition locations). }
$$




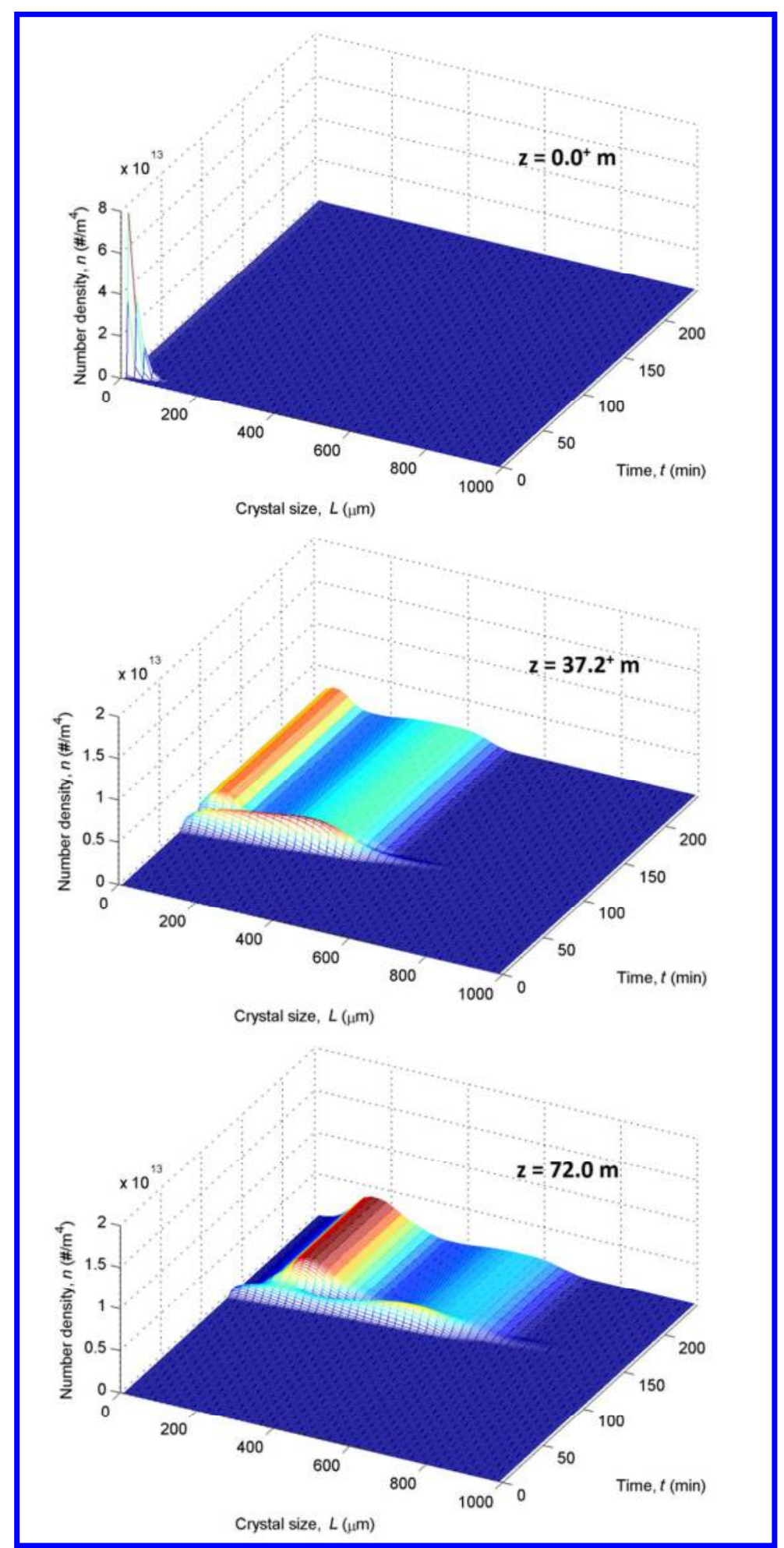

Figure 9. Dynamic simulation of CSD in MSMA-PFC for Case $3(m=4)$. 
Figure 10. Main solute concentration at the inlet during seeded start-up of MSMA-PFC for Case

$$
3(m=4) \text {. }
$$

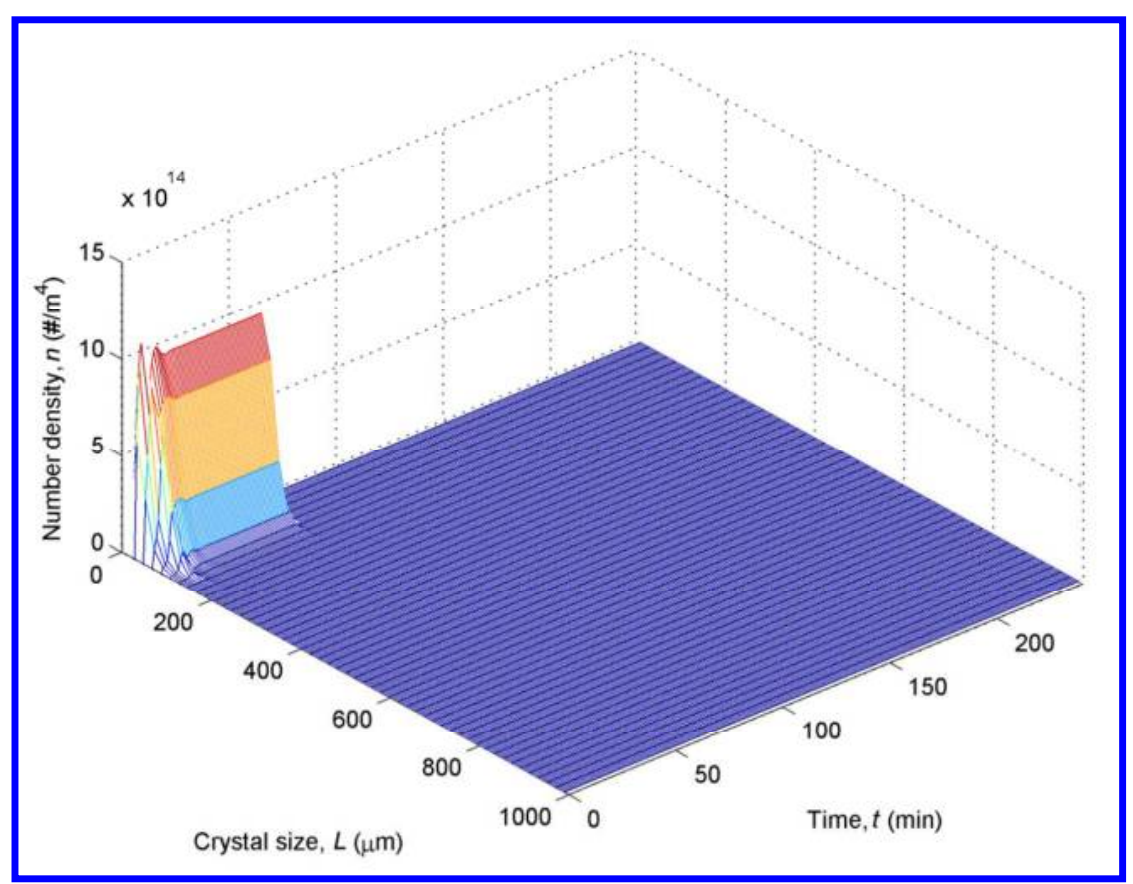

Figure 11. Crystal size distribution at the inlet during seeded start-up of MSMA-PFC for Case 3

$$
(m=4) \text {. }
$$




\section{TABLES}

Table 1. Summary of the three case studies.

\begin{tabular}{|c|c|c|c|c|c|c|}
\hline Case & $\mathbf{m}$ & $\mathbf{U}$ & A & $\begin{array}{c}\mathbf{L}_{43} \\
(\mu \mathrm{m})\end{array}$ & CV & $\begin{array}{c}\mathrm{C}_{\mathrm{ZN}} \\
(\mathrm{kg} / \mathrm{kg})\end{array}$ \\
\hline \multirow{6}{*}{1} & 1 & [1] & {$[1.000]$} & 278.5 & 0.182 & 0.0795 \\
\hline & 2 & {$\left[\begin{array}{ll}1 & 61\end{array}\right]$} & {$[0.500,0.500]$} & 273.3 & 0.160 & 0.0798 \\
\hline & 3 & 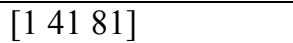 & {$[0.333,0.333,0.333]$} & 374.7 & 0.150 & 0.0804 \\
\hline & 4 & {$\left[\begin{array}{llllllllllllll}1 & 3 & 1 & 6 & 1 & 91\end{array}\right]$} & {$[0.250,0.250,0.250,0.250]$} & 369.7 & 0.301 & 0.0806 \\
\hline & 5 & {$\left[\begin{array}{llllll}1 & 25 & 49 & 73 & 97\end{array}\right]$} & {$[0.200,0.200,0.200,0.200,0.200]$} & 327.1 & 0.196 & 0.0808 \\
\hline & 6 & {$\left[\begin{array}{llllllll}1 & 2 & 4 & 41 & 61 & 81 & 101\end{array}\right]$} & {$[0.166,0.166,0.166,0.166,0.166,0.166]$} & 361.5 & 0.188 & 0.0812 \\
\hline \multirow{6}{*}{2} & 1 & [1] & [1.000] & 278.5 & 0.182 & 0.0795 \\
\hline & 2 & {$\left[\begin{array}{ll}1 & 61\end{array}\right]$} & {$[0.245,0.755]$} & 494.9 & 0.251 & 0.0805 \\
\hline & 3 & {$\left[\begin{array}{llll}1 & 4 & 1 & 81\end{array}\right]$} & {$[0.272,0.376,0.353]$} & 439.5 & 0.226 & 0.0806 \\
\hline & 4 & {$\left[\begin{array}{lllll}1 & 31 & 6 & 1 & 91\end{array}\right]$} & {$[0.242,0.025,0.733,0.001]$} & 499.0 & 0.247 & 0.0805 \\
\hline & 5 & {$\left[\begin{array}{llllll}1 & 25 & 49 & 73 & 97\end{array}\right]$} & {$[0.256,0.018,0.369,0.341,0.016]$} & 470.3 & 0.225 & 0.0806 \\
\hline & 6 & {$\left[\begin{array}{llllllll}1 & 2 & 4 & 41 & 61 & 81 & 101\end{array}\right]$} & {$[0.233,0.035,0.079,0.546,0.106,0.001]$} & 483.5 & 0.229 & 0.0806 \\
\hline \multirow{6}{*}{3} & 1 & [1] & [1.000] & 278.5 & 0.182 & 0.0795 \\
\hline & 2 & {$[1,62]$} & {$[0.246,0.754]$} & 497.2 & 0.248 & 0.0806 \\
\hline & 3 & {$\left[\begin{array}{lll}1 & 48 & 62\end{array}\right]$} & {$[0.238,0.135,0.627]$} & 511.7 & 0.248 & 0.0806 \\
\hline & 4 & {$\left[\begin{array}{llllllllllll}1 & 46 & 54 & 63\end{array}\right]$} & {$[0.241,0.074,0.135,0.551]$} & 519.6 & 0.223 & 0.0806 \\
\hline & 5 & {$\left[\begin{array}{lllllll}1 & 53 & 61 & 62 & 64\end{array}\right]$} & {$[0.241,0.135,0.114,0.156,0.356]$} & 520.0 & 0.230 & 0.0806 \\
\hline & 6 & {$\left[\begin{array}{lllllllllll}1 & 19 & 50 & 56 & 63 & 67\end{array}\right]$} & {$[0.237,0.003,0.071,0.111,0.516,0.063]$} & 521.1 & 0.238 & 0.0806 \\
\hline
\end{tabular}

